ARTICLE

Received 20 May 2015 | Accepted 17 Jul 2015 | Published 27 Aug 2015

\title{
Efficiently photo-charging lithium-ion battery by perovskite solar cell
}

Jiantie $X u^{1, \star}$, Yonghua Chen ${ }^{1, \star} \&$ Liming Dai ${ }^{1}$

Electric vehicles using lithium-ion battery pack(s) for propulsion have recently attracted a great deal of interest. The large-scale practical application of battery electric vehicles may not be realized unless lithium-ion batteries with self-charging suppliers will be developed. Solar cells offer an attractive option for directly photo-charging lithium-ion batteries. Here we demonstrate the use of perovskite solar cell packs with four single $\mathrm{CH}_{3} \mathrm{NH}_{3} \mathrm{Pbl}_{3}$ based solar cells connected in series for directly photo-charging lithium-ion batteries assembled with a $\mathrm{LiFePO}_{4}$ cathode and a $\mathrm{Li}_{4} \mathrm{Ti}_{5} \mathrm{O}_{12}$ anode. Our device shows a high overall photo-electric conversion and storage efficiency of $7.80 \%$ and excellent cycling stability, which outperforms other reported lithium-ion batteries, lithium-air batteries, flow batteries and super-capacitors integrated with a photo-charging component. The newly developed self-chargeable units based on integrated perovskite solar cells and lithium-ion batteries hold promise for various potential applications.

\footnotetext{
${ }^{1}$ Center of Advanced Science and Engineering for Carbon (Case4Carbon), Department of Macromolecular Science and Engineering, Case Western Reserve University, Cleveland, Ohio 44106, USA. * These authors contributed equally to this work. Correspondence and requests for materials should be addressed to L.D. (email: liming.dai@case.edu).
} 
T he importance of developing new types of energy conversion and storage systems is evident by the everincreasing human reliance on energy-based appliances, the rapidly diminishing fossil fuels and the continuously growing environmental concerns. The global energy consumption by automobiles, along with the associated greenhouse-gas emission, has been accelerating at an alarming rate due to the rapid increase in world population and economic expansion worldwide. Unlike traditional vehicles relying heavily on the fossil fuels, electric vehicles or plug-in hybrid electric vehicles hold great promise to solve current energy and environmental challenges. With recent advance in the development of eco-friendly rechargeable lithium-ion batteries (LIBs) of higher power and energy densities ${ }^{1}$, battery electric vehicles (BEVs) using LIB pack(s) for propulsion have attracted a great deal of interest ${ }^{2}$. Of particular interest, Tesla has recently demonstrated the use of a battery pack consisting of 7,000 cylindrical LIB cells (each with $18 \mathrm{~mm}$ in diameter $\times 65 \mathrm{~mm}$ in length) connected in series and parallel to power electric vehicles (http://www.cadex.com/en/batteries/safety-of-lithium-ion-

batteries), opening a new era of transportation with $\mathrm{BEVs}^{3}$. Although the excellent electrochemical performance of LIBs, including their high specific capacity, power and energy density, and rate capability, could ensure a long cruise duration, short charging time and low total cost of a BEV, implementing the BEV technology in our daily life is still a big challenge as it requires a cross-country network of BEV-charging stations. This will not only cause inflexibilities to travel plans but also inevitably increase the total cost of the BEV technology. Therefore, the large-scale practical application of BEVs cannot be realized unless LIBs with self-charging suppliers will be achieved.

The solar cell technology that can generate electricity from the sunlight ${ }^{4,5}$, could offer a viable approach to 'self-charging' of LIBs wherever needed. With the free and abundant sunlight that provides about 10,000 times more energy to the Earth than we consume, solar cells can ensure sustainable access to electrical power for charging LIBs anywhere around the world with no air pollution, hazardous waste or noise, and they requires little upkeep. If solar cells can be used for directly photo-charging LIBs, therefore, the BEV technology could be marketed for large-scale applications even without the presence of a cross-country network of charging stations. Although conceptually promising, photo-charging of batteries, including LIBs, with solar cells has been much less discussed than photo-charging super-capacitors and is far from practical so far (Supplementary Table 1) ${ }^{6-23}$. This is because all the limited number of the photo-charging LIB devices reported to date exhibited a very low overall photo-electric storage-conversion efficiency and poor cycling stability (Supplementary Table 1).

One of the critical issues needs to be addressed for efficient photo-charging of LIBs is to enhance the usually low current density and power-conversion efficiency associated with most current solar cells, particularly polymer solar cells. In this regard, the recent availability of high-performance perovskite solar cells (PSCs) ${ }^{5,24-31}$ could not only facilitate the development of highly efficient (up to $\sim 20 \%$ ) and low cost solar cells for practical applications but also allow for the integration of PSCs into various energy systems. Herein, we report the first use of PSC packs with four single $\mathrm{CH}_{3} \mathrm{NH}_{3} \mathrm{PbI}_{3}$ PSCs connected in series for directly photo-charging LIBs assembled with a $\mathrm{LiFePO}_{4}$ cathode and $\mathrm{Li}_{4} \mathrm{Ti}_{5} \mathrm{O}_{12}$ anode. The fabricated PSC-LIB units were shown to possess a high overall photo-electric conversion and storage efficiency of $7.80 \%$ and excellent cycling stability-outperformed all other reported LIBs, lithium-air batteries, flow batteries and super-capacitors integrated with a photo-charging component. This work clearly indicates that the PSC-LIB units developed in this study hold great promise for potential applications as self-chargeable batteries to power the BEVs and various portable electronics.

\section{Results}

Working mechanism of a PSCs-LIB unit. Figure 1 schematically shows the fabricated system for photo-charging a LIB by PSCs connected in series. As shown in Fig. 1, the photogenerated free holes and electrons within the PSCs flow into the cathode and anode of the LIB, respectively. This current flow from the PSC to the close circuited LIB (top, Fig. 1) leads to charging the LIB through oxidative extraction of lithium ions from the cathode (for example, olive structure $\mathrm{LiFePO}_{4}$ ), followed by reductive insertion onto the anode (for example, spinel structure $\left.\mathrm{Li}_{4} \mathrm{Ti}_{5} \mathrm{O}_{12}\right)$. The energy (charge) stored during the charging process can be released to external loading (bottom, Fig. 1) by turning S1 off and S2 on, which is accompanied by a simultaneous back flow of lithium ions from the anode to cathode.

Fabrication and performance of PSCs. To construct the PSCs-LIB system shown in Fig. 1, we first fabricated PSCs with a device structure of ITO (indium tin oxide)/poly(3,4-ethylenedioxythiophene):poly(styrenesulfonate) (PEDOT:PSS) (40 nm)/ $\mathrm{CH}_{3} \mathrm{NH}_{3} \mathrm{PbI}_{3}$ (perovskite) $(375 \mathrm{~nm}) /[6,6]$-phenyl-C61-butyric acid methyl ester (PC61BM) $(100 \mathrm{~nm}) / \mathrm{Ca}(20 \mathrm{~nm}) / \mathrm{Al}(100 \mathrm{~nm})$. Supplementary Fig. 1 schematically shows structures of the perovskite material and solar cell device while their characterization and fabrication details can be found in Supplementary Note 1 and Supplementary Methods. The $\mathrm{CH}_{3} \mathrm{NH}_{3} \mathrm{PbI}_{3}$ perovskite layer was prepared according to our previously reported layer-by-layer process $^{29}$. Briefly, we first thermally evaporated a thin $(125 \mathrm{~nm})$ layer of lead iodide $\left(\mathrm{PbI}_{2}\right)$ onto a PEDOT:PSS layer pre-coated on an ITO/glass substrate (Supplementary Fig. 1). Subsequently, we dipped the $\mathrm{PbI}_{2}$ into a solution of $\mathrm{CH}_{3} \mathrm{NH}_{3} \mathrm{I}$ in 2-propanol $\left(10 \mathrm{mg} \mathrm{ml}^{-1}\right)$ to transfer it into a layer of $\mathrm{CH}_{3} \mathrm{NH}_{3} \mathrm{PbI}_{3}$ perovskite.

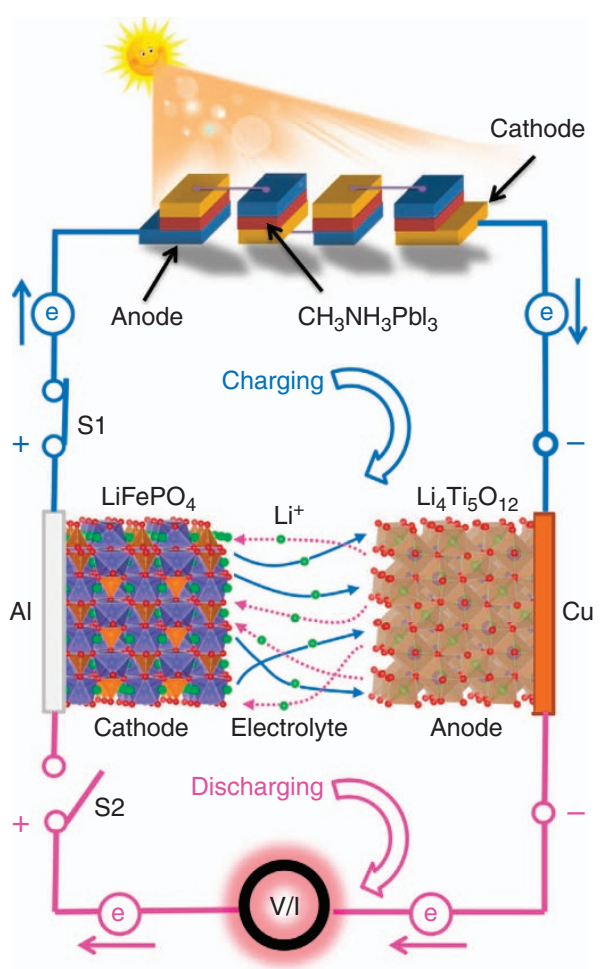

Figure 1 | Photo-charging a LIB by PSCs. Schematic diagram of the fabricated system of PSC-LIB. 
Similarly, a second $\mathrm{PbI}_{2}$ layer $(125 \mathrm{~nm})$ was thermally evaporated onto the newly formed $\mathrm{CH}_{3} \mathrm{NH}_{3} \mathrm{PbI}_{3}$ perovskite film, followed by dipping into the $\mathrm{CH}_{3} \mathrm{NH}_{3} \mathrm{I}$ solution to form the second layer of $\mathrm{CH}_{3} \mathrm{NH}_{3} \mathrm{PbI}_{3}$ perovskite intimately contacted with the underlying pre-formed $\mathrm{CH}_{3} \mathrm{NH}_{3} \mathrm{PbI}_{3}$ perovskite layer. The above process was repeated three times to form an interface-free uniform $\mathrm{CH}_{3} \mathrm{NH}_{3} \mathrm{PbI}_{3}$ perovskite layer of a desirable total thickness for outstanding photovoltaic performance required for photo-charging LIBs. The individual layer thickness of $\mathrm{PbI}_{2}$ was optimized at $125 \mathrm{~nm}$ as a thinner layer $\mathrm{PbI}_{2}(<125 \mathrm{~nm})$ cannot ensure pinhole free, whereas a thicker $\mathrm{PbI}_{2}(>125 \mathrm{~nm})$ cannot be totally transformed into $\mathrm{CH}_{3} \mathrm{NH}_{3} \mathrm{PbI}_{3}$ perovskite (Supplementary Fig. 2a). A typical scanning electron microscopy image for the resultant $\mathrm{CH}_{3} \mathrm{NH}_{3} \mathrm{PbI}_{3}$ perovskite film is given in Supplementary Fig. 2b, which shows a uniform, pinhole-free morphology. Supplementary Fig. $2 \mathrm{c}$ shows a typical X-ray diffraction pattern with peaks at $13.68^{\circ}, 24.01^{\circ}, 28.04^{\circ}$ and $42.80^{\circ}$ characteristic of the (110), (202), (220) and (330) diffractions, respectively, from the tetragonal $\mathrm{CH}_{3} \mathrm{NH}_{3} \mathrm{PbI}_{3}$ perovskite, indicating a complete transformation of the three-layered $\mathrm{PbI}_{2}$ with a total thickness of $375 \mathrm{~nm}$ into the $\mathrm{CH}_{3} \mathrm{NH}_{3} \mathrm{PbI}_{3}$ perovskite film. Further evidence for the complete conversion of the $\mathrm{PbI}_{2}$ layer into the $\mathrm{CH}_{3} \mathrm{NH}_{3} \mathrm{PbI}_{3}$ perovskite film came from the optical absorption spectrum given in Supplementary Fig. 2d, which shows a broad band with an onset at $770 \mathrm{~nm}$ characteristic of the $\mathrm{CH}_{3} \mathrm{NH}_{3} \mathrm{PbI}_{3}$ perovskite. The chemical composition of the $\mathrm{CH}_{3} \mathrm{NH}_{3} \mathrm{PbI}_{3}$ perovskite film was measured by X-ray photoelectron spectroscopy (XPS). Supplementary Fig. 3a shows an XPS survey spectrum while Supplementary Fig. 3b-e reproduce the high-resolution XPS spectra of $\mathrm{C} 1 \mathrm{~s}, \mathrm{I} 3 \mathrm{~d}, \mathrm{~Pb} 4 \mathrm{f}$ and $\mathrm{N} 1 \mathrm{~s}$, respectively. Numerical data from the XPS measurements are listed in Supplementary Table 2. As expected, the atomic ratio of $\mathrm{I} / \mathrm{Pb}$ was found to be 2.85, which is close to the stoichiometric value of 3 .

Before the system integration, we have further investigated the PSC performance. Figure 2a,b show typical current density-voltage $(J-V)$ characteristics for a single PSC and four of them connected in series, respectively. For the single PSC, a short-circuit photocurrent density of $22.85 \mathrm{~mA} \mathrm{~cm}^{-2}$, open-circuit voltage of $0.96 \mathrm{~V}$, fill factor of 0.71 and power-conversion efficiency (PCE; $\eta_{1}$, Method calculation 1) of $15.67 \%$ were obtained. The short-circuit current density matched well with the current density of $21.93 \mathrm{~mA} \mathrm{~cm}^{-2}$ calculated from the incident photon-to-current efficiency (IPCE) spectrum (Supplementary Fig. 4). To ensure a sufficiently high operating voltage for directly photo-charging LIBs, we then fabricated a PSC pack by connecting four single cells in series (top, Fig. 1). The detailed $J_{\mathcal{c}}, V_{\mathrm{oc}}, \mathrm{FF}$ and $\eta_{1}$ of these four single cells were shown in Supplementary Figs 5a and 6. As a result, we obtained a short-circuit photocurrent density of
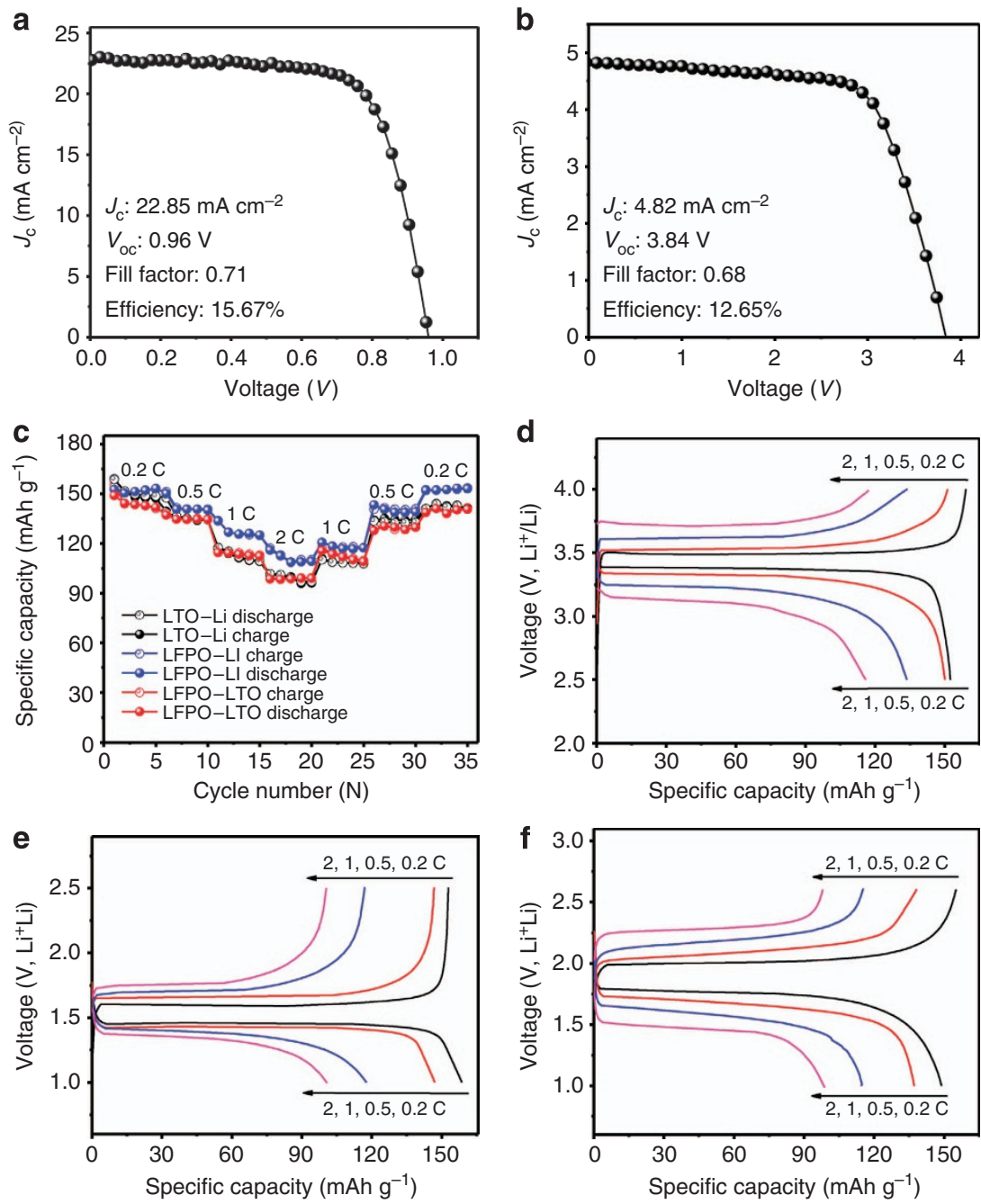

Figure 2 | Performance of PSCs and LIBs. (a) J-V curve for single PSC. (b) A typical J-V curve for the connected PSCs unit with four single PSCs connected in series. (c) Rate capabilities of LFPO-Li, LTO-Li and LFPO-LTO cells measured at various $\mathrm{C}-$ rates $(1 \mathrm{C}=170 \mathrm{mAg}-1)$ in the voltage ranges of $2.5-4.0$, 1.0-3.0 and 1.0-2.6 V, respectively. (d-f) Typical charge-discharge curves of (d) LFPO-Li, (e) LTO-Li and (f) LFPO-LTO cells. 
$4.82 \mathrm{~mA} \mathrm{~cm}^{-2}$ (per the total area of four PSCs), open-circuit voltage of $3.84 \mathrm{~V}$, fill factor of 0.68 and PCE of $12.65 \%$ for the connected PSC unit (Fig. 2b). While the connected PSC unit exhibited sufficiently good performance with a high open-circuit voltage $(3.84 \mathrm{~V})$ for photo-charging LIBs, its long-term operation stability was tested, along with the corresponding single cells, to be superb even up to $720 \mathrm{~h}$ (in Ar atmosphere).

Fabrication and electrochemical performance of LIBs. Owing to their high energy density, excellent thermal and chemical stability, long cycling life and superior safety, $\mathrm{LiFePO}_{4}$ (LFPO) and $\mathrm{Li}_{4} \mathrm{Ti}_{5} \mathrm{O}_{12}$ (LTO) have been widely regarded as promising cathode and anode materials, respectively, for the next generation of high-energy LIBs attractive for $\mathrm{BEVs}^{1,32,33}$. In this regard, we have fabricated a full LIB cell based on $\mathrm{LiFePO}_{4}-1 \mathrm{M} \mathrm{LiFP}$ in ethylene carbonate/dimethyl carbonate/diethyl carbonate $(\mathrm{v} / \mathrm{v} / \mathrm{v}$ : $1: 1: 1)-\mathrm{Li}_{4} \mathrm{Ti}_{5} \mathrm{O}_{12}$ with a working voltage range of $1.0-2.6 \mathrm{~V}$ (Methods). The structure and morphology of the LFPO and LTO electrodes were confirmed by X-ray diffraction measurements (Supplementary Fig. 7a,b) and scanning electron microscopy images (Supplementary Fig. 7c,d). The electrochemical performance of a LFPO-Li or LTO-Li half cell (lithium foil as a counter and reference electrode) and a full cell of LFPO-LTO (with a LFPO/LTO mass ratio of $\sim 1.1$ ) was given in Fig. $2 c-f$. Specifically, Fig. $2 c$ shows the rate capability of the LFPO and LTO electrodes with respect to a full LFPO-LTO cell at the same C-rates. As can be seen, the LFPO and LTO electrodes exhibited initial charge/discharge capacities of $159.1 / 152.5$ and $152.8 /$ $158.6 \mathrm{mAhg}^{-1}$ at $0.2 \mathrm{C}\left(1 \mathrm{C}=170 \mathrm{mAg}^{-1}\right)$, and $151.2 / 150.1$ and $139.4 / 147.5 \mathrm{mAh} \mathrm{g}^{-1}$ at $0.5 \mathrm{C}$, respectively. Figure $2 \mathrm{~d}$,e show typical charge-discharge profiles for the LFPO-Li and LTO-Li half cells, respectively, at various C-rates, showing the flat voltage profiles without significant over-potential at the C-rate $\leq 0.5 \mathrm{C}$. Similar flat discharge-charge profiles were observed for the LFPO-LTO cell. As shown in Fig. 2c,f, the LFPO-LTO cell exhibited a good cycling stability over a wide range of C-rates from 0.2 to $2 \mathrm{C}$ with average charge/discharge capacities of $145.3 / 144.3 \mathrm{mAhg}^{-1}$ at $0.2 \mathrm{C}$ and $135.7 /$ $135.1 \mathrm{mAhg}^{-1}$ at $0.5 \mathrm{C}$.

Performance of PSCs-LIB device. Having carried out systematic performance evaluations for both the PSCs and LFPO/LTO-based LIBs, we used the PSC unit with four single PSCs connected in series to directly photo-charge a LFPO-LTO LIB at an current density of $0.5 \mathrm{C}\left(0.085 \mathrm{mAg}^{-1}, 1 \mathrm{C}=170 \mathrm{mAg}^{-1}\right)$, which matches well with the photogenerated current density from the PSC unit over the voltage range of $2.0-2.5 \mathrm{~V}$ (4.61-4.52 $\mathrm{mA} \mathrm{cm}^{-2}$ and $0.087-0.085 \mathrm{mAg}^{-1}$, Fig. 2b). Figure $3 \mathrm{a}$ shows photo-charge (blue lines) and galvanostatic discharge (black lines) curves of a LIB repeatedly photo-charged by the connected PSC unit (PSCs-LIB) for 10 cycles at $0.5 \mathrm{C}$ between 1.0 and $2.6 \mathrm{~V}$. To compare with the photo-charging, we also performed galvanostatic charge-discharge of the same LIB cell, using an automatic battery tester system (Land, China) as
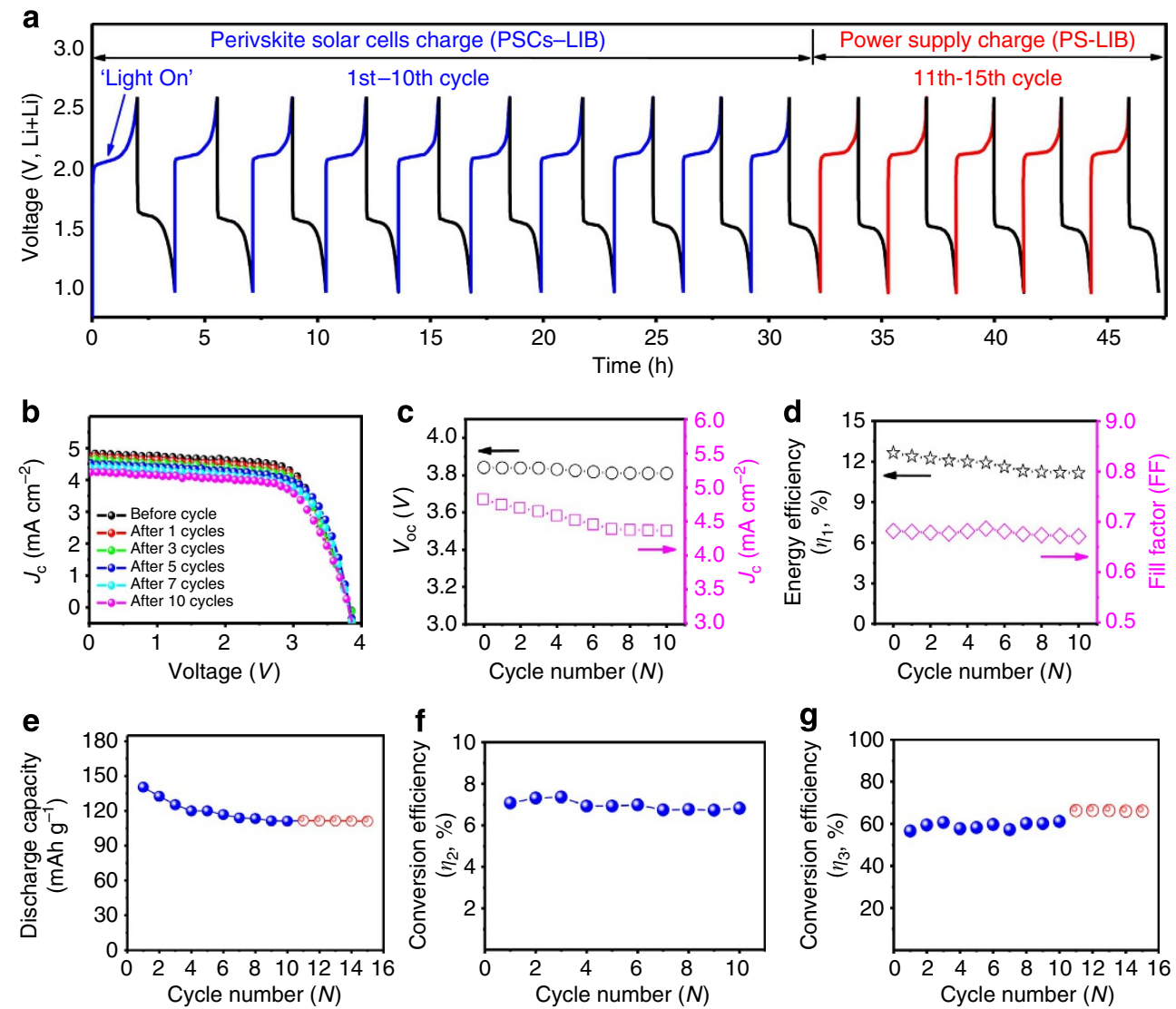

Figure 3 | Performance of fabricated PSCs-LIB and PS-LIB. (a) Voltage-time (V-t) curves of the PSCs-LIB device (blue and black lines at the 1st-10th cycles: charged at $0.5 \mathrm{C}$ using PSC and galvanostatically discharged at $0.5 \mathrm{C}$ using power supply. Red and black lines at the 11th-15th cycles: both galvanostatically charged and discharged at $0.5 \mathrm{C}$ using power supply). (b) $J-V$ curves, $(\mathbf{c}) V_{\mathrm{oc}}$ and $J_{\mathrm{c}^{\prime}}$ (d) fill factor (FF) and solar-to-electric PCE ( $\eta_{1}$ ) of the connected PSCs before and after various cycles. (e) Discharge capacity (Note, a slight variation was observed for the discharge duration at different cycle numbers), (f) overall photo-electric conversion efficiency of the PSCs-LIB device $\left(\eta_{2}\right)$ and $(\mathbf{g})$ energy storage (conversion) efficiency $\left(\eta_{3}\right)$ of LIB, as a function of the cycle number. 
power supply (PS) after the completion of the 10 photo-charge/ galvanostatic discharge cycles (PS-LIB, red lines in Fig. 3a). As shown in Fig. 3a, the PSCs-LIB and PS-LIB cells showed almost identical very stable discharge-charge curves over all the cycles, indicating excellent capabilities of the PSCs for photo-charging LIBs. Even after continued illumination under AM1.5G for $17.8 \mathrm{~h}$ over 10 repeated photo-charge and galvanostatic discharge cycles (Supplementary Fig. 8), the connected PSC unit showed only slight changes in all the photovoltaic characteristics, including $J_{\mathcal{C}}$, $V_{\mathrm{oc}}$ and FF, with a small decrease in PCE $\left(\eta_{1}\right)$ from 12.65 to $11.16 \%$ (Fig. 3b-d, Supplementary Table 3), corresponding to an average of $0.15 \%$ per cycle decay in $\eta_{1}$. The above observed operation stability was also confirmed by the high $\eta_{1}$ retention ( $\sim 93 \%$ ) obtained for single (Supplementary Fig. 9a-c) and connected PSCs out of the photo-charging system (Fig. 1, Supplementary Fig. 9d-f) even after $720 \mathrm{~h}$ testing in an Ar-filled glove box without any encapsulation protection. As seen in Fig. 3e (blue dots), the fabricated PSCs-LIB cell delivered an initial reversible capacity of $140.4 \mathrm{mAhg}^{-1}$ while maintained a reversible capacity of $111.6 \mathrm{mAh} \mathrm{g}^{-}$after 10 photo-charge and galvanostatic discharge cycles (that is, $79.49 \%$ initial capacity, $\sim 2.05 \%$ decay per cycle). This was followed by a highly reversible capacity of $111.1 \mathrm{mAhg}^{-1}$ during the PS-LIB process up to the 15th galvanostatic charge-discharge cycle (Fig. 3e, red dots).

In comparison, the galvanostatic charge-discharge cycles measured for fresh LFPO-Li, LTO-Li and LFPO-LTO cells at $0.5 \mathrm{C}$ in the voltage ranges of $2.5-4.0,1.0-3.0$ and $1.0-2.6 \mathrm{~V}$, respectively, for 30 cycles, using the automatic battery tester system as power supply (that is, PS), were given in Fig. 4. As expected, the fresh LFPO-LTO cell (Fig. 4a) using PS showed the similar charge-discharge $V$ - $t$ curves to that of (PSCs and PS)-LIB (Fig. 3a). As shown in Fig. 4b, the fresh cell delivered the initial, 11th, 15th and 30th reversible capacities of 141.6, 117.5, 115.5 and $115.2 \mathrm{mAh} \mathrm{g}^{-1}$, corresponding to an average capacity decay of $1.70 \%$ at the 10 th cycle, $1.85 \%$ at the 15 th cycle and $1.88 \%$ at the 30th cycle, during the galvanostatic charge and discharge cycles. As shown in Fig. 4b, the cycling stability of LFPO-LTO cell was significantly improved after initial few cycles due to the enhanced compatibility between the electrode and electrolyte. Along with the almost identical electrochemical behaviour (Fig. 4a), the close discharge capacity and average capacity decay observed for both the PS-LIB and PSCs-LIB indicate, once again, the excellent photo-charging capability of the PSCs and high cycling stability of the LFPO-LTO LIBs.

To gain insights into the power-conversion and storage efficiencies, we calculated the overall photo-electric conversion efficiency of the fabricated PSCs-LIB system $\left(\eta_{2}\right)$ by dividing the discharge energy of the LFP-LTO cell shown in Fig. 1 by the illumination energy (Method calculation 2). Figure 3f (blue dots) shows a rather stable $\eta_{2}$ for the PSCs-LIB system during the 10 photo-charge and galvanostatic discharge cycles at $0.5 \mathrm{C}$, with a maximum $\eta_{2}$ of $7.36 \%$ and an average $\eta_{2}$ of $6.97 \%$ (Supplementary Table 4). Owing to a low potential polarization between the charge and discharge voltage plateaus at lower C-rates (cf. Fig. 2f), the PSCs-LIB exhibited an increased $\eta_{2}$ with decreasing C-rate: $7.80 \%$ at $0.1 \mathrm{C}, 7.35 \%$ at $0.25 \mathrm{C}, 6.87 \%$ at $0.5 \mathrm{C}$, $6.47 \%$ at $0.75 \mathrm{C}$ and $6.11 \%$ at $1 \mathrm{C}$ (Supplementary Table 5). To our best knowledge, the overall $7.80 \%$ photo-electric conversion efficiency $\left(\eta_{2}\right)$ for the PSCs-LIB unit outperformed all other reported LIBs $^{7}$, lithium-air batteries ${ }^{20}$, flow batteries ${ }^{11,14}$ and super-capacitors ${ }^{10,19,23}$ integrated with a photo-charging component, such as a solar cell (Supplementary Table 1). Furthermore, the energy storage efficiency $\left(\eta_{3}\right)$ of the LIB in the PSCs-LIB was calculated by $\eta_{2} / \eta_{1}$ (that is, Method calculation 3 , blue dots in Fig. $3 \mathrm{~g}$ ) to be $\sim 60 \%$ while $\eta_{3}$ for the LIB in the PSLIB was calculated to be $\sim 66 \%$ (Method calculation 4 , red dots in Fig. 3g). The single fresh LFPO-LTO LIB showed a $\eta_{3}$ of $\sim 71 \%$ and an average Coulombic efficiency of $\sim 99.5 \%$ (Fig. 4 c). Clearly, therefore, the newly developed PSCs-LIB system possesses the highest $\eta_{1}, \eta_{2}$ and $\eta_{3}$ among all reported photo-chargeable energy devices, including batteries and capacitors (Supplementary Table 1), holding great promise as a self-chargable power supplier for BEVs and many other optoelectronic systems.

\section{Discussion}

As can be seen from above, the solar cell technology offers a viable option to self-charge LIBs for potentially marketing the BEV technology for large-scale applications. However, all the photo-charging LIB devices reported to date exhibited a very low overall photo-electric storage-conversion efficiency and poor
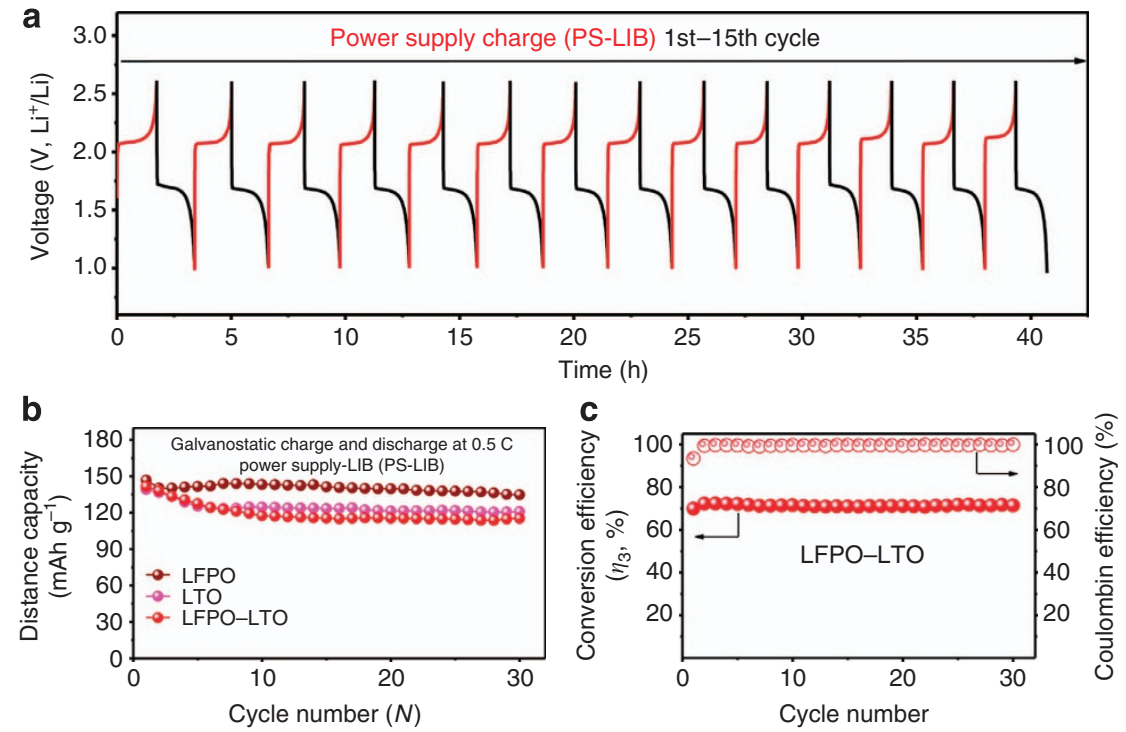

Figure 4 | Cycling performance of the LTO, LFPO and LFPO-LTO. (a) $V$ - $t$ curves of a fresh LFPO-LTO cell measured at $0.5 \mathrm{C}$ in the voltage range of 1.0-2.6 V for 15 cycles. (b) Cycling performance of LTO, LFPO and LFPO-LTO cells measured at $0.5 \mathrm{C}$ in the voltage ranges of 1.0-3.0, 2.5-4.0 and 1.0-2.6 V, respectively, for 30 cycles. (c) Conversion efficiency $\left(\eta_{3}\right)$ and Coulombic efficiency of LFPO-LTO for 30 cycles. 
cycling stability (Supplementary Table 1). We have, for the first time, demonstrated the use of PSC packs for directly photocharging LIBs. The solar cell pack with four single $\mathrm{CH}_{3} \mathrm{NH}_{3} \mathrm{PbI}_{3}$ PSCs connected in series showed an outstanding solar-to-electric PCE of $12.65 \%$ (15.67\% for the single cell), while the full LIB cell assembled with the $\mathrm{LiFePO}_{4}$ cathode and $\mathrm{Li}_{4} \mathrm{Ti}_{5} \mathrm{O}_{12}$ anode exhibited a high specific capacity and rate capability. The fabricated PSCs-LIB units were demonstrated to possess a high photo-electric conversion and storage efficiency of $7.80 \%$ and excellent cycling stability under continued illumination with AM1.5G for $17.8 \mathrm{~h}$. For practical applications, repeatable and reliable fabrication of the PSCs-LIB units with good performance is another important issue needs to be addressed. Supplementary Figs 5b, 6 and 10 show a good repeatability for reliable fabrication of PSCs and integration of the resultant PSCs units for efficient photo-charging LIBs. In addition, an excellent discharge rate capability at various discharge rates was observed for the LFPO-LTO cell in the PSCs-LIB system (Supplementary Fig. 11). Both the photo-charged PSCs-LIB and the PS-LIB cells, gavanostatically charged and discharged at $0.5 \mathrm{C}$, exhibited a similar rate capability from 0.1 to $1 \mathrm{C}$ (Supplementary Fig. 12), further indicating a highly stable PSCs-LIB system. To our best knowledge, the newly developed PSCs-LIB units outperformed all other reported LIBs, lithium-air batteries, flow batteries and super-capacitors integrated with a photo-charging component (Supplementary Table 1). These excellent results clearly indicate that the PSCs-LIB developed in this study hold great promise for potential applications as self-chargeable batteries to power the $\mathrm{BEVs}$ and various portable electronics.

\begin{abstract}
Methods
Materila preparation. The commercial $\mathrm{LiFePO}_{4}$ cathode and $\mathrm{Li}_{4} \mathrm{Ti}_{5} \mathrm{O}_{12}$ anode materials were purchased from the MTI Corporation (USA). The PEDOT:PSS, $\mathrm{PbI}_{2}$ and PC61BM were purchased from Clevious, Sigma Aldrich and Nano-C, respectively. $\mathrm{CH}_{3} \mathrm{NH}_{3} \mathrm{I}$ was synthesized according to the reported procedures ${ }^{31}$.
\end{abstract}

PSCs-LIB device assemble. The cathode (anode) was fabricated by blending $\mathrm{LiFePO}_{4}$, LFPO $\left(\mathrm{Li}_{4} \mathrm{Ti}_{5} \mathrm{O}_{12}, \mathrm{LTO}\right)$ with acetylene black carbon and polyvinylidene difluoride at a weight ratio of 90:5:5, respectively. $N$-methyl-2-pyrrolidone was used as the solvent. The slurries were stirred in a sealed glass bottle for $3 \mathrm{~h}$. The resultant $\mathrm{LiFePO}_{4}$ and $\mathrm{Li}_{4} \mathrm{Ti}_{5} \mathrm{O}_{12}$ slurries were then coated on $\mathrm{Al}$ and $\mathrm{Cu}$ foils, respectively. The LIBs were assembled as the CR 2032 coin-type cells in an Ar-filled glove box. The LFPO-Li and LTO-Li half-cells were assembled from $\mathrm{LiFePO}_{4}$ or $\mathrm{Li}_{4} \mathrm{Ti}_{5} \mathrm{O}_{12}$ with a mass loading of $11-13 \mathrm{mg} \mathrm{cm}^{-2}$ as the working electrode, using $\mathrm{Li}$ foils as the counter electrode and reference electrode, porous polypropylene film as separator and $1 \mathrm{M} \mathrm{LiPF}_{6}$ in a 1:1:1 (v/v/v) mixture of ethylene carbonate, dimethyl carbonate and diethyl carbonate as the electrolyte. The LFPO-LTO full cell was assembled by using LFPO and LTO as the cathode and anode, respectively. The LFPO-Li, LTO-Li and LFPO-LTO cells were measured using an automatic battery tester system (Land, China) as PS and photo-charged or galvanostatically charged and discharged at various current densities in the voltage ranges of 2.5-4.0, 1.0-3.0 and $1.0-2.6 \mathrm{~V}$, respectively $\left(1 \mathrm{C}=170 \mathrm{~mA} \mathrm{~g}^{-1}\right.$ for all three samples).

For the PSC construction, ITO glass substrates were cleaned sequentially with detergent, de-ionized water, acetone and iso-propanol, followed by drying with $\mathrm{N}_{2}$ flow and ultraviolet-ozone treatment for $15 \mathrm{~min}$. The PEDOT:PSS solution (Al4083 from H. C. Starck) was spin-cast onto ITO electrodes at 5,000 r.p.m. for 40 s. The PEDOT:PSS film was annealed at $140^{\circ} \mathrm{C}$ for $10 \mathrm{~min}$ to remove residual water. The ITO/PEDOT:PSS substrate was then transferred to evaporator in an Ar-filled glove box for $\mathrm{PbI}_{2}$ evaporation ( $125 \mathrm{~nm}$ ), followed by dipping the $\mathrm{PbI}_{2}$-deposited substrate into a solution of $\mathrm{CH}_{3} \mathrm{NH}_{3} \mathrm{I}$ in 2-propanol $\left(10 \mathrm{mg} \mathrm{ml}^{-1}\right)$ for $40 \mathrm{~s}$ to form the $\mathrm{CH}_{3} \mathrm{NH}_{3} \mathrm{PbI}_{3}$ perovskite layer and being rinsed with 2-propanol for $10 \mathrm{~s}$. Similarly, a second $\mathrm{PbI}_{2}$ layer was thermally evaporated onto the pre-formed first layer of $\mathrm{CH}_{3} \mathrm{NH}_{3} \mathrm{PbI}_{3}$ perovskite film, followed by dipping into the $\mathrm{CH}_{3} \mathrm{NH}_{3} \mathrm{I}$ solution to form the second layer of $\mathrm{CH}_{3} \mathrm{NH}_{3} \mathrm{PbI}_{3}$ perovskite, and the process was repeated for three times for a desired thickness. The $\mathrm{CH}_{3} \mathrm{NH}_{3} \mathrm{PbI}_{3}$ perovskite was then thermally annealed at $100^{\circ} \mathrm{C}$ for $10 \mathrm{~min}$ in the glove box to complete crystallization for the perovskite film. After the thermal annealing, PC61BM in chlorobenzene solution $\left(17 \mathrm{mg} \mathrm{ml}^{-1}\right)$ was deposited onto the perovskite layer by spin coating at 1,000 r.p.m. for $60 \mathrm{~s}$. Finally, the device was transferred to the evaporator for thermal evaporation of $\mathrm{Ca}(20 \mathrm{~nm})$ and $\mathrm{Al}(100 \mathrm{~nm})$ at $10^{-7}$ torr. All the devices were tested in an Ar-filled glove box using a Keithley 2400 source meter and a Newport Oriel sol 2A solar simulator $(300 \mathrm{~W})$. We used the $91150 \mathrm{~V}$ Reference Cell and Meter (ORIEL instrument) to calibrate the light intensity to be $100 \mathrm{~mW} \mathrm{~cm}^{-2}$ before the device testing. The device performance parameters were obtained from the current-voltage curves of the solar cells under illumination. The IPCE was measured on a Solar Cell Measurement System from PV Measurement Inc. The PSCs (single PSC or four single PSCs connected in series) thus fabricted were kept in the glove box under high-purity Ar gas for further electrochemical measurements and long-time rest measurements. The PSCs-LIB units were fabricated by integrating PSCs and a LIB into the system, as shown in Fig. 1.

Calculations. 1. The energy-conversion efficiency of the PSC $\left(\eta_{1}\right)$ :

$$
\eta_{1}(\mathrm{PSC})=J_{\mathrm{c}} \times \mathrm{FF} \times V_{\mathrm{oc}} / P \times 100 \%
$$

where FF, $V_{\mathrm{oc}}, J_{\mathrm{c}}$ and $\mathrm{P}$ are fill factor, open-circuit voltage $(\mathrm{V})$, short-circuit current density $\left(\mathrm{mA} \mathrm{cm}^{-2}\right)$ and incident light power density $\left(100 \mathrm{~mW} \mathrm{~cm}^{-2}\right)$, respectively.

2. The energy-conversion and storage efficiencies for the entire PSCs-LIB integrated unit:

$$
\eta_{2}(\mathrm{PSCs}-\mathrm{LIB})=E_{\mathrm{d}} /(P \times S \times t) \times 100 \%
$$

where $E_{\mathrm{d}}, P, S$ and $t$ are discharge energy of LIB (mWh, from Land machine), light power density $\left(100 \mathrm{mWcm}^{-2}\right)$, effective area of PSCs in series $\left(\mathrm{cm}^{-2}\right)$ and photo-charge time $(\mathrm{h})$, respectively.

3. The energy storage efficiency for PSC to photo-charge LIB:

$$
\eta_{3}(\mathrm{PSCs}-\mathrm{LIB})=\eta_{2} / \eta_{1} \times 100 \%
$$

4. The energy storage efficiency for galvanostatically charging LIB with Land machine as power supply (PS-LIB):

$$
\eta_{3}(\mathrm{PS}-\mathrm{LIB})=E_{\mathrm{d}} / E_{\mathrm{c}} \times 100 \%
$$

where $E_{\mathrm{d}}$ and $E_{\mathrm{c}}$ are the discharge and charge energy $(\mathrm{mWh})$, in which the LIB was galvanostatically charged using Land machine.

\section{References}

1. Goodenough, J. B. \& Kim, Y. Challenges for rechargeable Li batteries. Chem. Mater. 22, 587-603 (2009).

2. Nykvist, B. \& Nilsson, M. Rapidly falling costs of battery packs for electric vehicles. Nat. Clim. Change 5, 329-332 (2015).

3. Castelvecchi, D. Will Tesla's battery change the energy market? Nature (2015).

4. Green, M. A. Solar Cells: Operating Principles, Technology, and System Applications (Prentice-Hall, 1982).

5. Lee, M. M., Teuscher, J., Miyasaka, T., Murakami, T. N. \& Snaith, H. J. Efficient hybrid solar cells based on meso-superstructured organometal halide perovskites. Science 338, 643-647 (2012).

6. Lo, C.-W., Li, C. \& Jiang, H. Direct solar energy conversion and storage through coupling between photoelectrochemical and ferroelectric effects. AIP Adv. 1, 042104 (2011).

7. Guo, W., Xue, X., Wang, S., Lin, C. \& Wang, Z. L. An integrated power pack of dye-sensitized solar cell and $\mathrm{Li}$ battery based on double-sided $\mathrm{TiO}_{2}$ nanotube arrays. Nano Lett. 12, 2520-2523 (2012).

8. Liu, P., Yang, H. X., Ai, X. P., Li, G. R. \& Gao, X. P. A solar rechargeable battery based on polymeric charge storage electrodes. Electrochem. Commun. 16, 69-72 (2012).

9. Yan, N. F., Li, G. R., Pan, G. L. \& Gao, X. P. TiN nanotube arrays as electrocatalytic electrode for solar storable rechargeable battery. J. Electrochem. Soc. 159, A1770-A1774 (2012).

10. Fu, Y. et al. Integrated power fiber for energy conversion and storage. Energ. Environ. Sci. 6, 805-812 (2013).

11. Liu, P. et al. A solar rechargeable flow battery based on photoregeneration of two soluble redox couples. ChemSusChem 6, 802-806 (2013).

12. Yang, Z. et al. An integrated device for both photoelectric conversion and energy storage based on free-standing and aligned carbon nanotube film. J. Mater. Chem. A 1, 954-958 (2013).

13. Zhang, X., Huang, X., Li, C. \& Jiang, H. Dye-sensitized solar cell with energy storage function through $\mathrm{PVDF} / \mathrm{ZnO}$ nanocomposite counter electrode. Adv. Mater. 25, 4093-4096 (2013).

14. Yan, N., Li, G. \& Gao, X. Solar rechargeable redox flow battery based on $\mathrm{Li}_{2} \mathrm{WO}_{4} / \mathrm{LiI}$ couples in dual-phase electrolytes. J. Mater. Chem. A 1, 7012-7015 (2013).

15. Chen, X. et al. A novel "energy fiber" by coaxially integrating dye-sensitized solar cell and electrochemical capacitor. J. Mater. Chem. A 2, 1897-1902 (2014).

16. Westover, A. S. et al. Direct integration of a supercapacitor into the backside of a silicon photovoltaic device. Appl. Phys. Lett. 104, 213905 (2014).

17. $\mathrm{Xu}$, J. et al. Integrated photo-supercapacitor based on $\mathrm{Bi}$-polar $\mathrm{TiO}_{2}$ nanotube arrays with selective one-side plasma-assisted hydrogenation. Adv. Func. Mater. 24, 1840-1846 (2014).

18. Zhang, Z. et al. Integrated polymer solar cell and electrochemical supercapacitor in a flexible and stable fiber format. Adv. Mater. 26, 466-470 (2014).

19. Pan, S. et al. Wearable solar cells by stacking textile electrodes. Angew. Chem. Int. Ed. 53, 6110-6114 (2014). 
20. Yu, M., Ren, X., Ma, L. \& Wu, Y. Integrating a redox-coupled dye-sensitized photoelectrode into a lithium-oxygen battery for photoassisted charging. Nat. Commun. 5, 5111 (2014).

21. Takshi, A., Yaghoubi, H., Tevi, T. \& Bakhshi, S. Photoactive supercapacitors for solar energy harvesting and storage. J. Power Sources 275, 621-626 (2015).

22. Shi, C. et al. An "all-in-one" mesh-typed integrated energy unit for both photoelectric conversion and energy storage in uniform electrochemical system. Nano Energy 13, 670-678 (2015).

23. Xu, X. et al. A power pack based on organometallic perovskite solar cell and supercapacitor. ACS Nano 9, 1782-1787 (2015)

24. Burschka, J. et al. Sequential deposition as a route to high-performance perovskite-sensitized solar cells. Nature 499, 316-319 (2013).

25. Zhou, H. et al. Interface engineering of highly efficient perovskite solar cells. Science 345, 542-546 (2014).

26. Luo, J. et al. Water photolysis at $12.3 \%$ efficiency via perovskite photovoltaics and Earth-abundant catalysts. Science 345, 1593-1596 (2014).

27. Im, J.-H., Jang, I.-H., Pellet, N., Grätzel, M. \& Park, N.-G. Growth of $\mathrm{CH}_{3} \mathrm{NH}_{3} \mathrm{PbI}_{3}$ cuboids with controlled size for high-efficiency perovskite solar cells. Nat. Nanotech. 9, 927-932 (2014).

28. Jeon, N. J. et al. Solvent engineering for high-performance inorganic-organic hybrid perovskite solar cells. Nat. Mater. 13, 897-903 (2014).

29. Chen, Y., Chen, T. \& Dai, L. Layer-by-ayer growth of $\mathrm{CH}_{3} \mathrm{NH}_{3} \mathrm{PbI}_{3}-{ }_{\mathrm{x}} \mathrm{Cl}_{\mathrm{x}}$ for highly efficient planar heterojunction perovskite solar cells. Adv. Mater. 27, 1053-1059 (2015).

30. Jeon, N. J. et al. Compositional engineering of perovskite materials for high-performance solar cells. Nature 517, 476-480 (2015).

31. Xiao, Z. et al. Giant switchable photovoltaic effect in organometal trihalide perovskite devices. Nat. Mater. 14, 193-198 (2015).

32. Yamada, A., Chung, S.-C. \& Hinokuma, K. Optimized $\mathrm{LiFePO}_{4}$ for lithium battery cathodes. J. Electrochem. Soc. 148, A224-A229 (2001).

33. Zhao, L., Hu, Y. S., Li, H., Wang, Z. \& Chen, L. Porous $\mathrm{Li}_{4} \mathrm{Ti}_{5} \mathrm{O}_{12}$ coated with $\mathrm{N}$-doped carbon from ionic liquids for Li-ion batteries. Adv. Mater. 23 1385-1388 (2011).

\section{Acknowledgements}

We are grateful for financial support from the National Science Foundation (NSF-CMMI-1400274, DMR-1106160)

\section{Author contributions}

J.X. and L.D. conceived the concept and designed the experiments; J.X and Y.C. fabricated the LIBs and PSCs, respectively, performed the materials characterization, assembled the PSCs-LIB and PS-LIB devices, carried out their electrochemical measurements and analysed the data; L.D. was responsible for planning and supervising the project; J.X., Y.C. and L.D. co-wrote the paper and all authors discussed the results and commented on the manuscript.

\section{Additional information}

Supplementary Information accompanies this paper at http://www.nature.com/ naturecommunications

Competing financial interests: The authors declare no competing financial interests.

Reprints and permission information is available online at http://npg.nature.com/ reprintsandpermissions/

How to cite this article: $\mathrm{Xu}$, J. et al. Efficiently photo-charging lithium-ion battery by perovskite solar cell. Nat. Commun. 6:8103 doi: 10.1038/ncomms 9103 (2015).

(c) (i)

This work is licensed under a Creative Commons Attribution 4.0 International License. The images or other third party material in this article are included in the article's Creative Commons license, unless indicated otherwise in the credit line; if the material is not included under the Creative Commons license, users will need to obtain permission from the license holder to reproduce the material. To view a copy of this license, visit http://creativecommons.org/licenses/by/4.0/ 